\title{
Effect of Stem Age on the Response of Stem Diameter Variations to Plant Water Status in Tomato
}

J. Hanssens, T. De Swaef and K. Steppe

Laboratory of Plant Ecology

Ghent University

Ghent

Belgium

H. Marien

Katholieke Hogeschool van de Kempen

Geel

Belgium
K. Goen and F. De Nayer

Proefcentrum Hoogstraten

Meerle

Belgium

\section{Wittemans}

Proefstation voor de groenteteelt

Sint Katelijne Waver

Belgium

J. Desmedt

Flemish institute for technological research (VITO)

Mol

Belgium

Keywords: Solanum lycopersicum, tissue extensibility, elastic modulus, mechanistic modelling, model calibration, horticulture, sensitivity analysis

\begin{abstract}
Plant water status plays a major role in glasshouse cultivation of tomato (Solanum lycopersicum L.). New climate control technologies alter the glasshouse climate and make it less dependent on solar radiation. However, irrigation strategies are still often based on solar radiation sums. In order to maintain a good plant water status, it is interesting to use plant-based methods such as monitoring sap flow (F) or stem diameter variations (SDV). Though SDV give important information about plant water status, an unambiguous interpretation might be difficult because other factors such as stem age, fruit load and sugar content of the stem also affect SDV. In this study, an analysis of the effect of stem age on the response of SDV to water status was performed by calibration of a mechanistic flow and storage model. This allowed us to determine how parameter values changed across the growing season. Tissue extensibility decreased over the growing season resulting in a lower growth rate potential, whereas daily cycles of shrinking and swelling of the stem became more pronounced towards the end of the growing season. Parameters were then adapted to time-dependent variables and implemented in the model, allowing long term simulation and interpretation of SDV. Sensitivity analysis showed that model predictions were very sensitive to initial sucrose content of the phloem tissue and the parameters related to plastic growth.
\end{abstract}

\section{INTRODUCTION}

A good plant water status is essential for good production and fruit quality in glasshouse cultivation of tomato (Solanum lycopersicum L.). Current irrigation strategies are often based on solar radiation sums. During the last years, lots of efforts have been made in order to make greenhouse cultivation more energy-efficient. Due to the 
introduction of new climate control technologies, the glasshouse climate has become less dependent on solar radiation. As such, the link between plant water uptake and radiation could be expected to change. In order to maintain a good plant water status, it is therefore interesting to use plant-based methods because the plant itself is the best indicator of its water status (Jones, 2004). The use of stem diameter variations (SDV) for irrigation scheduling has already been applied in fruit trees and tomato (Goldhamer and Fereres, 2001; Fereres and Goldhamer, 2003; Intrigliolo and Castel, 2004; Gallardo et al., 2006; De Swaef et al., 2009). Stems show a daily pattern of reversible shrinking and swelling as a result of changes in hydration levels in combination with irreversible radial expansion when turgor pressure exceeds the threshold value $\Gamma$ at which wall yielding occurs (Steppe et al., 2006). Interpretation of SDV over longer periods of time can be difficult since SDV are also influenced by other factors than plant water status such as the sugar content of the stem, fruit load and stem age (Intrigliolo and Castel, 2005; De Swaef and Steppe, 2010; Fernández and Cuevas, 2010; Ortuño et al., 2010). The response of SDV-derived indices such as maximum daily shrinkage (MDS) and stem growth rate (SGR) to different irrigation treatments is extensively studied for fruit trees, whereas far less is known for herbaceous species such as tomato (Gallardo et al., 2006). Altering relationships between MDS and water status across the growing season have been reported for different fruit trees (Goldhamer and Fereres, 2001; Intrigliolo and Castel, 2004) suggesting changes in tissue elasticity during the growing season. Maximum daily shrinkage (MDS) and stem growth rate (SGR) of tomato stems showed a different response to water deficit with crop age (Gallardo et al., 2006). This highlights the need for more knowledge about how stem age influences SDV in order to interpret long term SDV data and to be able to use them for irrigation purposes.

Steppe et al. (2006) developed a mechanistic flow and storage model for trees which allows simulation of stem water potential and turgor pressure using sap flow as input variable. The model is also able to simulate the pattern of SDV. Calibration of this model for different periods of the growing season showed that parameter values for young beech and oak trees changed as a function of time (Steppe et al. 2008). This showed the need for recalibration of the model for different periods of the growing season in order to enable good simulations of SDV. This mechanistic flow and storage model developed for trees was recently modified for tomato (De Swaef and Steppe, 2010).

This study aims to gain a deeper understanding about how stem age influences stem diameter growth and the response of stem diameter variations to plant water status in tomato. Therefore the modified mechanistic flow and storage model was calibrated for different periods across the growing season in order to determine which parameters are influenced by stem age. An attempt was made to adapt these parameters to timedependent variables, allowing long term simulation and interpretation of the response of stem diameter variations to plant water status.

\section{MATERIALS AND METHODS Plant Material}

Tomato plants (Solanum lycopersicum 'Bonaparte') were grown in a glasshouse compartment at the Horticulture Research Centre, Meerle, Belgium. Plants were sown on November 6, 2008 and transplanted into rockwool slabs on January 7, 2009 at an initial density of 2.5 stems $\mathrm{m}^{-2}$. Later on during the growing season, one side-shoot per three plants was allowed to develop, resulting in a plant density of 3.3 stems $\mathrm{m}^{-2}$. Plants were provided with a nutrient solution using a drip irrigation system. First two trusses were 
pruned to 5 fruits per truss, whereas from the third truss on, 6 fruits were allowed to develop.

\section{Plant Physiological Measurements}

During the 2009 growing season, two plants were continuously monitored. Sap flow (F) was measured at the bottom of the stem below the first leaf using a heat balance sap flow sensor (Model SGA 13-WS, Dynamax Inc., Houston, TX, USA), installed according to the operation manual (van Bavel and van Bavel, 1990). SDV were monitored with linear variable displacement transducers (LVDT) (Model LBB315-PA-100, Schaevitz, Hampton, VA, USA) attached to the plant just above the sap flow sensor, using custom-made stainless steel holders. Signals were logged every 30 seconds using a data logger (CR1000, Campbell Scientific Inc., Logan, Utah, USA). Plant physiological measurements started at Day Of the Year (DOY) 100 and continued up to DOY 273.

\section{Model simulation and calibration}

The mechanistic flow and storage model modified by De Swaef and Steppe (2010) was used in this study. Simulations were performed using the plant modelling software PhytoSim (Phyto-IT BVBA, Mariakerke, Belgium). Sap flow data from the 2009 growing season were used as input for the model. A sensitivity analysis was performed using a normalized sensitivity function:

$$
\frac{\Delta y}{\Delta \theta}=\frac{y(\theta+\Delta \theta)-y(\theta-\Delta \theta)}{2 \Delta \theta} \cdot \frac{\theta}{s c}
$$

with $\Delta$ the perturbation factor $(0.01)$, y the model variable, $\theta$ the model parameter and sc the variable dependent scaling factor, for which the average value of the corresponding variable was used. For evaluation, the mean square criterion $(\delta)$ was deduced from the sensitivity functions, indicating the sensitivity of the output variable to a single model parameter. In order to determine parameter values for each selected time period across the growing season, the mechanistic flow and storage model was calibrated using the SDV data collected during the 2009 growing season. The Simplex algorithm (Nelder and Mead, 1965) was used in order to minimize the weighted sum of squared errors between the model predictions and the measured SDV data. The obtained parameter values were then used to develop time-dependent relationships which could be included in the model.

\section{RESULTS AND DISCUSSION Evolution of stem diameter}

The pattern of SDV measured across the 2009 growing season is shown in Fig. 1. Radial stem growth is more pronounced in the beginning of the growing season and slows down as the growing season proceeds. This can be attributed to a decrease in tissue extensibility $(\phi)$ as the stem storage tissue ages. Daily shrinking and swelling of the stem is more pronounced later on in the growing season. The SDV time series show a rather unexpected depression between DOY 130 and DOY 200. This might be caused by an increasing fruit load, which alters sink relations between fruits and stem.

\section{Evolution of model parameters}

For calibration of the model, values for xylem hydraulic resistance $\left(\mathrm{R}^{\mathrm{X}}\right)$ and hydraulic resistance between xylem and storage compartment $\left(\mathrm{R}^{\mathrm{S}}\right)$ were considered constant throughout the growing season, whereas other parameter values were recalibrated in the different selected periods. These periods used for calibration of the 
mechanistic flow and storage model are defined by the grey vertical bars in Fig. 1. Fig. 2 gives the evolution of tissue extensibility $(\phi)$ across the growing season. $\phi$ shows an exponential decay, characterised by a $\phi_{\max }$ and a time constant $\tau$, remaining almost zero at the end of the growing season. $\phi$ decreases as stem ages, resulting in lower growth rate potential (Proseus et al., 1999). The decrease of $\phi$ affects the contribution of plastic and elastic growth to SDV across the growing season. As such, equal shrinking and swelling may indicate a different water status throughout the growing season.

Due to the depression in stem diameter (Fig. 1), model calibration results in values of $\phi$ near zero between DOY 130 and 170 after which $\phi$ strongly increased (Fig. 2). Because this decrease and subsequent increase in stem diameter was probably due to a change in fruit load rather than in tissue extensibility, values for this period were excluded to determine a time-dependent relation for $\phi$. Since measurements did not start until DOY 100 , no values for $\phi$ could be determined for the period before DOY 100. It can be assumed that $\phi$ shows a constant maximum value in the beginning of the growing season instead of an immediate exponential decrease. Therefore, it can be proposed that $\phi$ maintains a constant value until a certain time, after which it starts to decrease according to the relation shown in Fig. 2. A similar behaviour of wall extensibility was proposed for plastic growth of mango fruits (Lechaudel et al., 2007).

Calibration showed a decrease in $\varepsilon_{0}$, the proportionality constant between the elastic modulus $\varepsilon$ and the product of stem diameter and pressure potential (Génard et al., 2001) across the growing season (results not shown). This contrasts with the decrease in elasticity when tissues age. Fig. 1 showed that shrinking and swelling was more pronounced towards the end of the growing season when SGR is smaller. Gallardo et al. (2006) also found that tomato stems show more shrinking when growth rate is low. The more intense shrinking and swelling of the stem might also partly be due to changes in hydraulic resistance in the xylem or between the xylem and the storage compartment, though in this study these parameters were kept constant. Further research will have to point this out.

\section{Long term simulation of SDV}

The time-dependent relationships found by model calibration were implemented in the model. This allowed a simulation of SDV across the growing season (Fig. 1). Parameter values and initial conditions used for simulation are given in Table 1. A reasonably good agreement was found between measured and simulated SDV, though the model was not able to simulate the depression in stem growth between DOY 130 and 200. Daily cycles of shrinking and swelling were slightly overestimated at the beginning of the growing season and slightly underestimated towards the end. Overall, the model was able to make good predictions of stem diameter evolution.

The model appeared very sensitive to the initial sugar content of the stem storage compartment (Fig. 3), which pointed out the effect of sugar content of the stem on SDV. Sensitivity analysis also showed that simulated SDV were very sensitive to $\phi_{\max }, \tau$ and $\Gamma$, which are the parameters related to plastic growth. SDV appeared the least sensitive to $\mathrm{R}^{\mathrm{s}}$ and $\varepsilon_{0}$. Since a constant parameter was used for sucrose loading in the stem storage compartment, daily fluctuations in sugar loading were not incorporated which leads to some deviations between measured and simulated SDV behavior. This results in the simulation of a more constant growth, whereas measured SDV show altering periods of 
more and less intense plastic growth. In Fig. 1, this can be seen from the faster increase in simulated stem diameter at the beginning of the growing season.

Including time-dependent relations made it possible to simulate SDV over periods longer than one week. It allowed the model to simulate the change in maximum daily shrinkage (MDS) and daily stem growth rate (SGR) across the growing season.

\section{CONCLUSIONS}

Calibration of the mechanistic flow and storage model allowed determining timedependent relations for $\phi$ and $\varepsilon_{0}$ of tomato stems which allowed interpretation of stem diameter variations across longer time periods. Plastic growth ceased during the growing season, whereas shrinking and swelling became more pronounced towards the end of the growing season. The different contributions of plastic and elastic growth across the growing season led to a different response to water status. Implementation of timedependent relationships in the model allowed better simulations of SDV behaviour across the complete growing season. The simulation of SDV was very sensitive to initial sucrose content of the stem and the parameters related to plastic growth. The mechanistic model was able to simulate changes in MDS and SGR over the growing season.

\section{ACKNOWLEDGEMENTS}

The authors would like to thank IWT for funding granted to the first author and Philip Deman and Geert Favyts for their technical support. The authors are also indebted to LAVA, Priva and HortiMaX for financial support.

\section{Literature Cited}

De Swaef, T. and Steppe, K. 2010. Linking stem diameter variations to sap flow, turgor and water potential in tomato. Funct. Plant Biol. 37:429-438.

De Swaef, T., Steppe, K. and Lemeur, R. 2009. Determining reference values for stem water potential and maximum daily trunk shrinkage in young apple trees based on plant responses to water deficit. Agr. Water Manage. 96:541-550.

Fereres, E. and Goldhamer, D.A. 2003. Suitability of stem diameter variations and water potential as indicators for irrigation scheduling of almond trees. J. Hort. Sci. Biotech. 78:139-144.

Fernández, J.E. and Cuevas, M.V. 2010. Irrigation scheduling from stem diameter variations: A review. Agr. Forest Meteorol. 150:135-151.

Gallardo, M., Thompson, R.B., Valdez, L.C. and Fernández, M.D. 2006. Use of stem diameter variations to detect plant water stress in tomato. Irrig Sci. 24:241-255.

Génard, M., Fishman, S., Vercambre, G., Huguet, J.-G., Bussi, C., Besset, J. and Habib, R. 2001. A biophysical analysis of stem and root diameter variations in woody plants. Plant Physiol. 126:188-202.

Goldhamer, D.A. and Fereres, E. 2001. Irrigation scheduling protocols using continuously recorded trunk diameter measurements. Irrig Sci. 20:115-125.

Intrigliolo, D.S. and Castel, J.R. 2004. Continuous measurement of plant and soil water status for irrigation scheduling in plum. Irrig. Sci. 23:93-102.

Intrigliolo, D.S. and Castel, J.R. 2005. Usefulness of diurnal trunk shrinkage as a water stress indicator in plum trees. Tree Physiol. 26:303-311.

Jones, H.G. 2004. Irrigation scheduling: advantages and pitfalls of plant-based methods. J. Exp. Bot. 55:2427-2436. 
Lechaudel, M., Vercambre, G., Lescourret, F. Normand, F. and Génard, M. 2007. An analysis of elastic and plastic fruit growth of mango in response to various assimilate supplies. Tree Physiol. 27:219-230.

Nelder, J.A. and Mead, R. 1965. A simplex method for function minimization. Comput. J. 7:308-313.

Ortuño, M.F., Conejero, W., Moreno, F., Moriana, A., Intrigliolo, D.S., Biel, C., Mellisho, C.D., Pérez-Pastor, A., Domingo, R., Ruiz-Sánchez, M.C., Casadesus, J., Bonany, J. and Torrecillas, A. 2010. Could trunk diameter sensors be used in woody crops for irrigation scheduling? A review of current knowledge and future perspectives. Agric. Water Manage. 97:1-11.

Proseus, T.E., Ortegea, J.K.E. and Boyer, J.S. 1999. Separating growth from elastic deformation during cell enlargement. Plant Physiol. 119:775-784.

Steppe, K., De Pauw, D.J.W. and Lemeur, R. 2008. Validation of a dynamic stem diameter variation model and the resulting seasonal changes in calibrated parameter values. Ecol. Model. 218:247-259.

Steppe, K., De Pauw, D.J.W., Lemeur, R. and Vanrolleghem, P.A. 2006. A mathematical model linking tree sap flow dynamics to daily stem diameter fluctuations and radial stem growth. Tree Physiol. 26:257-273.

van Bavel, M.G. and van Bavel, C.H.M. 1990. Dynagage installation and operation manual. Dynamax Inc., Houston, TX.

\section{Tables}

Table 1. Values of model parameters and initial conditions used.

\begin{tabular}{|c|c|c|}
\hline Parameter & Definition & Value \\
\hline$\Psi^{\text {solution }}(\mathrm{MPa})$ & Water potential in the substrate & -0.15 \\
\hline$\Gamma(\mathrm{MPa})$ & Turgor threshold for wall yielding & 0.3 (De Swaef et al., 2009) \\
\hline $1(\mathrm{~m})$ & Length of studied stem segment & 1 \\
\hline $\mathrm{D}(\mathrm{m})$ & Initial stem diameter & 0.0144585 \\
\hline $\mathrm{a}(-)$ & Allometric factor & 0.8 \\
\hline $\mathrm{R}^{\mathrm{x}}\left(\mathrm{MPa} \mathrm{h} \mathrm{g} \mathrm{g}^{-1}\right)$ & $\begin{array}{l}\text { Hydraulic resistance in xylem } \\
\text { compartment }\end{array}$ & 0.0030448 \\
\hline $\mathrm{R}^{\mathrm{s}}\left(\mathrm{MPah} \mathrm{g} \mathrm{g}^{-1}\right)$ & $\begin{array}{l}\text { Hydraulic resistance between xylem } \\
\text { en storage compartment }\end{array}$ & 0.198065 \\
\hline $\mathrm{C}^{\mathrm{p}}(0)\left(\mathrm{g} \mathrm{g}^{-1}\right)$ & $\begin{array}{l}\text { Initial sucrose concentration in the } \\
\text { phloem }\end{array}$ & 0.127662 \\
\hline$S\left(\mathrm{~g} \mathrm{~h}^{-1}\right)$ & Sucrose loading in the phloem & 0.00025 \\
\hline$\phi_{\max }\left(\mathrm{MPa}^{-1} \mathrm{~h}^{-1}\right)$ & Maximum tissue extensibility & 0.0133 \\
\hline$\tau\left(h^{-1}\right)$ & $\begin{array}{l}\text { Time constant of tissue extensibility } \\
\text { decrease }\end{array}$ & -0.001242 \\
\hline$\varepsilon_{0}\left(\mathrm{~m}^{-1}\right)$ & $\begin{array}{l}\text { Proportionality constant for the bulk } \\
\text { elastic modulus of the phloem tissue }\end{array}$ & 11272 \\
\hline
\end{tabular}




\section{Figures}

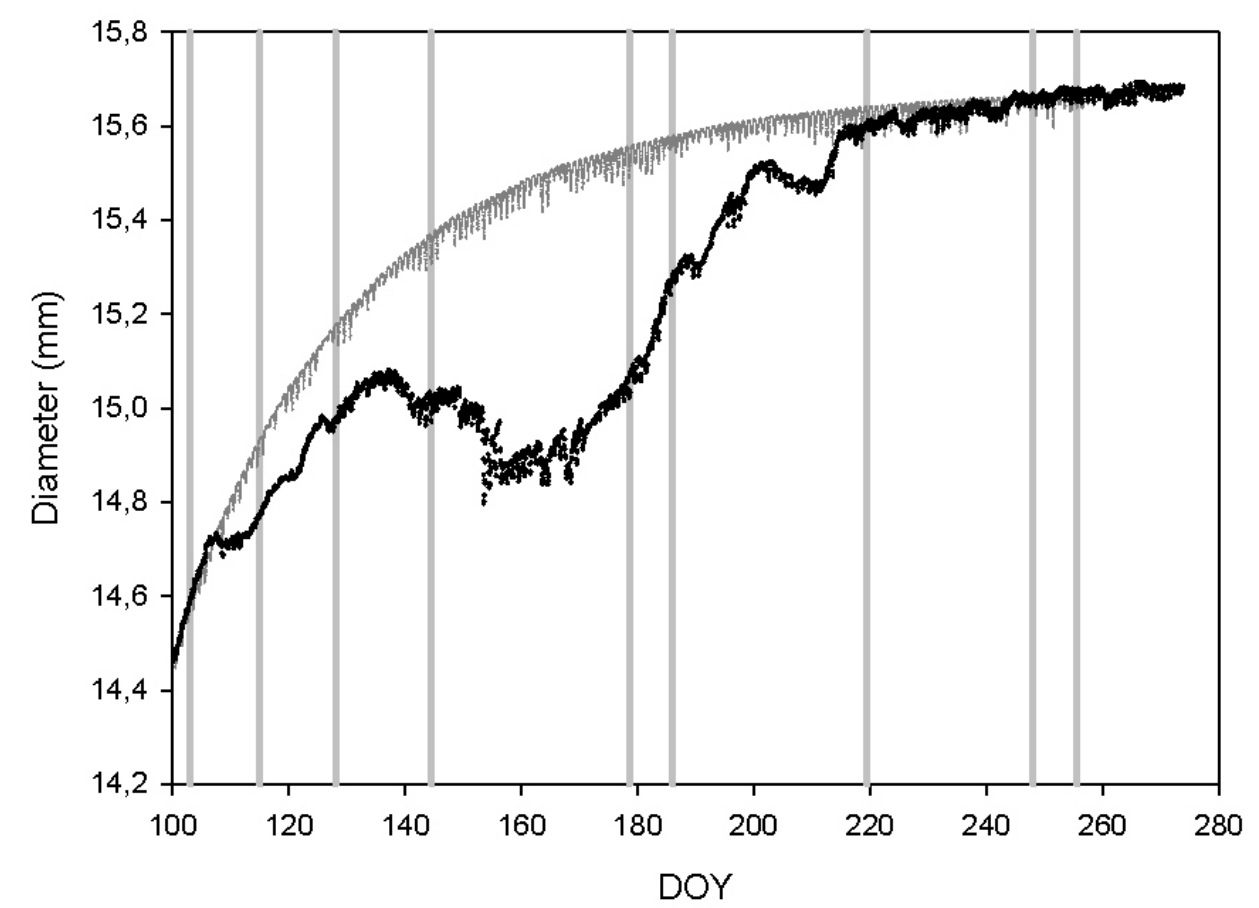

Fig. 1 Evolution of stem diameter variations across the growing season of 2009: measured data (black) and simulated data (grey).Vertical grey bars show the periods used for calibration of the mechanistic flow and storage model.

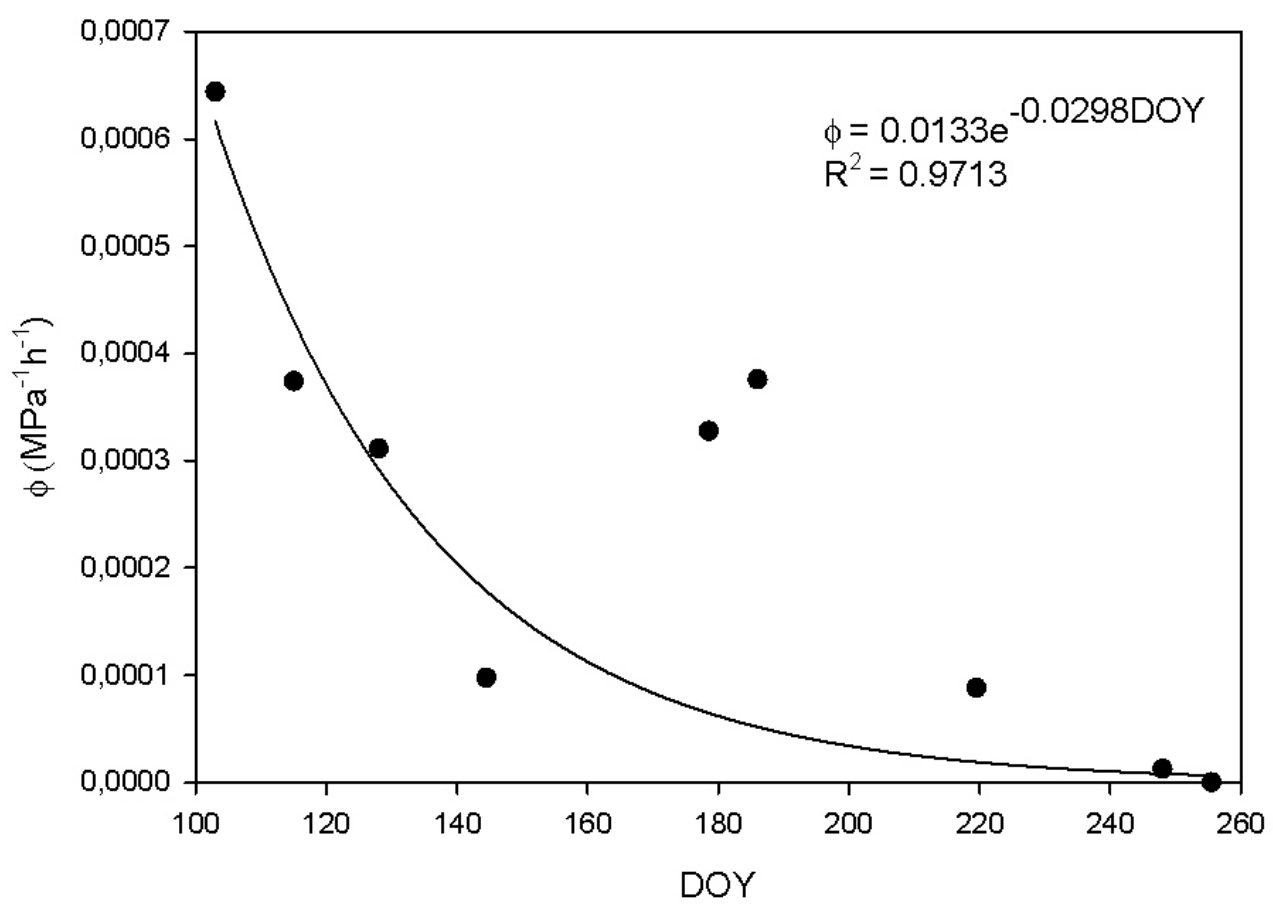

Fig. 2 Time evolution of tissue extensibility $(\phi)$ across the growing season. The timedependent relation was developed after exclusion of data points between DOY 130 and 200. 

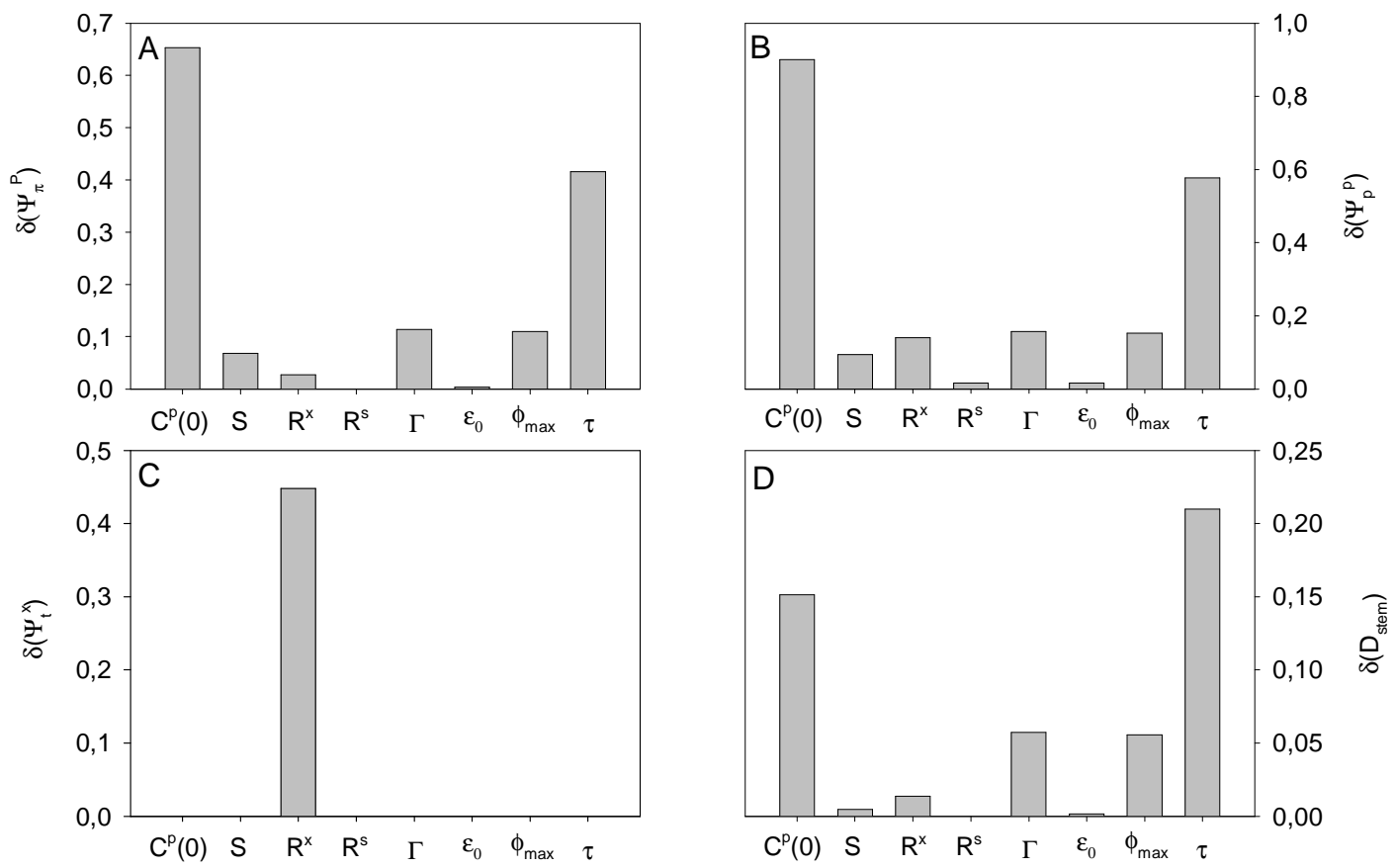

Fig. 3. Sensitivity index (mean square criterion $\delta$ ) of the output variables to model parameters and initial conditions. The evaluated variables were the phloem osmotic potential $\left(\Psi_{\pi}^{\mathrm{p}} ; \mathrm{A}\right)$, the phloem turgor potential $\left(\Psi_{\mathrm{p}}^{\mathrm{p}} ; \mathrm{B}\right)$, the xylem total water potential $\left(\Psi_{\mathrm{t}}{ }^{\mathrm{x}} ; \mathrm{C}\right)$ and the stem diameter $\left(\mathrm{D}_{\text {stem }} ; \mathrm{D}\right)$. The studied parameters are the initial sucrose concentration in the phloem $\left(\mathrm{C}^{\mathrm{p}}(0)\right)$, the sucrose loading in the phloem (S), the hydraulic resistance in the xylem compartment $\left(\mathrm{R}^{\mathrm{X}}\right)$, the hydraulic resistance between the xylem and storage compartment $\left(\mathrm{R}^{\mathrm{S}}\right)$, the turgor threshold value at which wall yielding occurs $(\Gamma)$, the proportionality constant for the bulk elastic modulus of the phloem tissue $\left(\varepsilon_{0}\right)$, the maximum tissue extensibility $\left(\phi_{\max }\right)$ and the time constant of tissue extensibility decrease $(\tau)$. 